\title{
O QUE É UMA PALAVRA: A CONSCIÊNCIA LINGUÍSTICA EM CRIANÇAS DE 6 A 11 ANOS FALANTES DO PORTUGUÊS BRASILEIRO
}

Cristiana lack Dias da Silva ${ }^{1}$

Aline Lorandi

\section{RESUMO}

O presente trabalho dedica-se ao estudo da consciência de palavra por crianças falantes do Português Brasileiro e à sua relação com os níveis de representação mental postulados pelo modelo de Redescrição Representacional (KARMILOFFSMITH, 1992). Foram desenvolvidos quatro testes com o objetivo de descrever os caminhos pelos quais as representações das crianças tornam-se mais manipuláveis e flexíveis ao longo do tempo, de modo a permitir a emergência do acesso consciente ao conhecimento implícito com relação à noção de palavra. Com aplicação dos testes e o levantamento das respostas espera-se obter uma amostra do que as crianças entendem por palavra e de como um conhecimento implícito para a mente torna-se explícito para a mente. Acreditamos na relevância deste trabalho por possibilitar uma explicação das representações mentais que fundamentam o conhecimento sobre consciência linguística apresentada pelas crianças.

Palavras-chave: Aquisição da linguagem. Consciência linguística. Modelo de redescrição representacional.

\section{INTRODUÇÃO}

O trabalho aqui apresentado debruça-se sobre a consciência linguística, o que ainda tem provocado muitas dúvidas e inquietações no que diz respeito à idade em que emerge, aos níveis de explicitude e quais comportamentos podem ser tomados como indicadores desse fenômeno (KARMILOFF-SMITH,1992; LORANDI; KARMILOFF-SMITH, 2012). 
Entendemos que definir palavra não é tarefa fácil e ao longo dos anos muitos teóricos têm argumentado que as crianças têm uma noção confusa do conceito de palavra e que pode não incidir sobre as fronteiras de uma única palavra. Nessa perspectiva, nosso trabalho é uma tentativa de entender o que a criança entende por palavra; perceber em que níveis da consciência linguística a criança está com relação à noção de palavra e captar as sutilezas no desenvolvimento da linguagem da criança.

Visando a compreender como se realiza esse processo, desenvolvemos quatro testes, baseados nos estudos de Karmiloff-Smiith (1992) e de BerthoudPapandropoulou (1978), que nos possibilitam perceber em que níveis de consciência linguística a criança está. Para a explicação dos resultados, adotamos o modelo de Redescrição Representacional (Karmiloff-Smith, 1992), que postula quatro níveis de representação, sendo um implícito e três explícitos, o que habilita o modelo perceber em que niveis de consciência linguística a criança está com relação à noção de palavra.

Espera-se com este estudo motivar outras e novas pesquisas sobre a consciência de palavra, assim como sua relação com outras questões relativas à língua, como, por exemplo, a aquisição da escrita, a leitura ou o desenvolvimento da consciência linguística de um modo geral.

\section{FUNDAMENTAÇÃO TEÓRICA}

Há uma grande variedade de estudos acerca da consciência linguística que procuram concentrar-se em aspectos linguísticos menores que a palavra e, em especial, sobre sua constituição fonológica (NAZZARI, 2010 LORANDI, 2011; MOTA, 2009, GOMBERT, 1992). Entretanto, percebe-se uma carência de estudos no que se refere a unidades maiores, como morfemas e palavras e, ainda mais, sobre unidades como a frase.

Nessa perspectiva, o presente trabalho é uma tentativa de entender o que a criança entende por/como palavra. Definir o que conta como uma palavra não é uma tarefa simples, como será apresentado na seção seguinte. Neste estudo, partimos da premissa de que a noção do que é uma palavra é construída de forma desenvolvimental. 


\title{
2.1 A noção de palavra
}

Definir o que é uma palavra pode constituir tarefa não muito fácil, pois "palavra" é um termo que usamos em nosso cotidiano da língua e parece simples denominá-la, porém como podemos constatar é uma atividade complexa. Esta afirmativa também se respalda nos argumentos de Rosa (2009, p.74) ao afirmar que

\begin{abstract}
O grande problema de definir palavra é ser esse termo passível de receber diferentes caracterizações nas diferentes áreas do estudo da linguagem, nem sempre resultantes na mesma unidade. Afora o uso na escrita, podemos entender palavra: (a) como uma unidade fonológica; (b) como o elemento mínimo da estrutura sintática; (c) como um elemento do vocábulo da língua.
\end{abstract}

Nessa perspectiva, definir palavra é uma atividade complexa para as crianças porque o termo "palavra", além de ser carregada de muitos sentidos, na literatura muito se tem argumentado que as crianças têm uma noção confusa do conceito de palavra e que pode não incidir sobre as fronteiras de uma única palavra. Segundo Rosa (2009), usamos em nosso cotidiano o termo "palavra", como "uma noção oriunda da escrita, que se aplica também à fala. Aprender a escrever também é aprender a identificar e a assinalar os limites da palavra gráfica” (ROSA, 2009, p.74). Ainda para a linguista, a palavra fonológica é denominada "a unidade formada por fonemas, sílabas e traços supra-segmentais - podendo ser maior do que aquilo que desejamos considerar uma palavra no estudo morfológico" (ROSA, 2009, p. 77).

Assim sendo, o termo "palavra" é difuso e, por definição, uma abstração gramatical. Com o lexema e a palavra morfossintática podemos dar conta das relações existentes entre vocábulos e as informações gramaticais que carregam (ROSA, 2009, p. 84).

Nesse sentido, constatamos que definir palavra é uma atividade complexa, pois o termo está carregado de identidade, valor semântico, e pelo simples fato que uma palavra possui vários sentidos. Essa afirmativa respalda-se nos argumentos de Dubois et al.(2006, p. 449-450), ao afirmar que

\footnotetext{
em linguística tradicional, a palavra é um elemento linguístico significativo composto de um ou mais fonemas; essa sequência é suscetível de uma transcrição escrita (ideogramática, silábica ou alfabética) compreendida entre dois espaços em branco; ela conserva sua forma, total ou parcialmente (no caso de flexão), em seus diversos empregos sintagmáticos; a palavra denota um objeto (substantivo) uma ação ou um estado (verbo), uma qualidade (adjetivo), uma relação (preposição).
} 


\subsection{A consciência linguística}

A consciência linguística envolve consciente reflexão, análise ou controle intencional sobre vários aspectos da linguagem - fonologia, semântica, morfologia, discurso, pragmática, fora dos processos inconscientes normais na produção ou compreensão.

Em outras palavras, além de seu domínio de uso da língua, as crianças gradualmente formam representações explícitas de vários níveis da linguagem. Após o trabalho pioneiro de Liberman e seus colaboradores (1971), a consciência linguística continuou a ser um tópico de interesse considerável para psicolinguistas de desenvolvimento. Há muitos níveis de consciência linguística que podem ser apresentados pelas crianças, no entanto carecemos de mais pesquisas para confrontar novos dados, porque não há um consenso de como e quando surge a consciência linguística e quais comportamentos podem ser tomados como indicadores desse fenômeno (PRATT; GRIEVE, 1984 apud LORANDI, 2011).

Segundo Karmiloff-Smith (1986, 1992), há diferentes níveis de explicitação que podem ser observados por toda fase de desenvolvimento da criança. E, por se tratar de desenvolvimento da fala, os fenômenos que evidenciam consciência mudam no decorrer do processo, não só em relação à verbalização do conhecimento, mas também em relação ao que é dito. Porém o que prevalece em discussões, independente da teoria adotada, é que a consciência linguística constitui um conhecimento implícito que se torna explícito.

É no modelo desenvolvido por Karmiloff-Smith (1992) que situaremos a noção de consciência tomada como suporte para a análise dos dados.

\subsection{0 modelo de redescrição representacional}

O modelo de Redescrição Representacional (KARMILOFF-SMITH, 1992), apresenta quatro níveis de representação, sendo um implícito e três explícitos, o que torna possível, com o modelo, captar as sutilezas no desenvolvimento da linguagem da criança (LORANDI, 2011; LORANDI; KARMILOFF-SMITH, 2012; LORANDI; KARMILOFF-SMITH, no prelo). Nessa perspectiva buscamos perceber em que momento do desenvolvimento da consciência linguística a criança está com relação à noção de palavra. 
Adotamos o modelo de Redescrição Representacional (KARMILOFF-SMITH, 1992) em uma tentativa de descrever os caminhos pelos quais as representações das crianças tornam-se mais manipuláveis e flexíveis ao longo do tempo, de modo a permitir a emergência do acesso consciente ao conhecimento implícito. Nesse contexto, o modelo aqui adotado vai além do simples implícito e explícito, pois consegue captar outros níveis no desenvolvimento da linguagem.

O modelo RR aqui adotado apresenta quatro níveis nos quais 0 conhecimento é redescrito e representado. Eles são: Implícito (I) em que a informação está totalmente voltada para o input externo, disponível como um todo, mas não analisável em suas partes. No Explícito 1 (E1), as representações são explícitas, mas ainda não disponíveis para acesso consciente, tampouco para o relato verbal. No Explícito 2 (E2), as representações explícitas estão disponíveis para acesso consciente, mas não para relato verbal, já no Explícito 3 (E3) as representações são explícitas, disponíveis para acesso consciente e para relato verbal.

Segundo Karmiloff-Smith (1992), essas diferentes formas de representação não constituem estágios relacionados à idade, e sim ciclos que se aplicam dentro de diferentes microdomínios com o passar do tempo. Em outras palavras, isso significa que, no momento em que um determinado nível é atingido, o conhecimento é redescrito de uma forma que se torna acessível para o próximo nível.

\section{METODOLOGIA}

Para realizar esse trabalho, optamos pela coleta de dados de caráter transversal. A pesquisa foi realizada na escola em que estudam os participantes, que também disponibilizou uma sala, para que pudéssemos fazer as anotações e também gravar em vídeo. A escolha das crianças se deu a partir da idade e também pela autorização dos pais e/ou responsáveis. Buscamos agrupar as crianças, além da idade, também por séries. Na seção seguinte, apresentaremos mais informações sobre os informantes e os instrumentos. 


\subsection{Participantes}

Os testes foram aplicados a 12 crianças, de idades entre 6 e 11 anos, sendo 04 crianças de 6 a 7 anos, 4 crianças de 8 a 9 anos e 4 crianças de 10 a 11 anos. Todos os informantes são estudantes de uma escola pública de Bagé. As crianças são oriundas do próprio bairro e arredores da escola, pertencentes à classe média baixa. As atividades foram desenvolvidas na escola, escritas e gravadas em vídeo para posterior estudo e análise das coletas.

\subsection{Os testes}

Para atingir nosso objetivo, desenvolvemos quatro experimentos. O primeiro deles é uma adaptação do trabalho já realizado por Karmiloff-Smith (1992) e tem por objetivo a identificação, pela criança, do que é uma palavra, dentre um conjunto de itens de classe aberta (nomes, verbos) e de classe fechada (artigos, preposições, pronomes, etc). Após a identificação, a criança era convidada a explicar sua resposta. Esse tipo de procedimento é entendido como uma atividade off-line de processamento verbal.

O segundo e o terceiro experimentos também são adaptações para o português de um trabalho de Karmiloff-Smith et al. (1992), que fora aplicado para crianças falantes do francês. Neste trabalho, adaptamos os testes, criando histórias, e as crianças foram convidadas a ouvi-las atentamente e a responder "qual a última coisa que ouviram" ou "qual a última palavra que ouviram". Esse tipo de procedimento é entendido como uma atividade on-line de processamento verbal. Nessa perspectiva, cada vez que $O$ narrador interrompe, e a criança é solicitada a dar uma resposta, ela deverá extrair, do seu conhecimento linguístico, uma unidade (palavra ou coisa) e repeti-la.

Já o quarto e último experimento baseou-se nos estudos de BerthoudPapandropoulou (1978), que apontava resultados que crianças muito jovens falham em apreciar a natureza arbitrária da relação entre o signo linguístico e o objeto que ele representa, o que sugeria que as crianças confundem o número de referentes do mundo real com o número de palavras, em outras palavras. Isso significa que a tarefa de contar palavras em frases implica que a criança pode confundir limites de 
palavras com limites de frases. As frases foram citadas e, em seguida, 0 pesquisador fez a seguinte pergunta: Quantas palavras têm na frase que eu disse?

A seguir, detalharemos os contextos experimental e procedimental dos testes, deixando em anexo o material desenvolvido para sua aplicação.

\subsubsection{Contexto experimental dos testes}

As crianças foram levadas individualmente para uma sala reservada, cedida pela escola, em que estiveram com o pesquisador, que aplicou os testes, e com um pesquisador auxiliar, que realizou a filmagem. Cada aplicação durou em torno de 30 minutos. Ao final, as crianças eram levadas de volta à sala de aula.

\subsubsection{Contextos procedimentais}

\subsubsection{Teste 1 - Responda para o Chico}

O pesquisador explicou para as crianças que essa é uma brincadeira em que vamos interagir com o ursinho Chico. Chico é um ursinho muito curioso, que adora aprender e fazer perguntas. Posteriormente o pesquisador leu 10 palavras, sendo 5 palavras de classe aberta e 5 de classe fechada e deu a seguinte tarefa: "Agora, responda para o Chico, pois Chico quer saber se "amigo", por exemplo, pode ser considerada uma palavra ou não e por quê".

\subsubsection{Teste 2: Sapeca e Pirulito}

Primeiramente o experimentador explicou a cada uma das crianças que leria uma história curta para familializá-las com a técnica experimental. Foi informado que, durante a leitura, o pesquisador faria pausas e, a seguir, perguntaria: qual foi a última palavra que eu disse? Toda atividade foi realizada individualmente, transcrita e gravada em vídeo para posterior estudo da pesquisa.

A história foi narrada pelo experimentador. Nessa história as pausas foram inseridas no meio das frases, seguindo palavras pré-selecionadas a partir de categorias de palavras de classe aberta e de classe fechada. A história continha 10 palavras-alvo, sendo 5 palavras da categoria classe aberta e 5 palavras da categoria 
classe fechadas.Vale ressaltar que nenhum treinamento foi dado anteriormente sobre as categorias de palavras de classe aberta e de classe fechada. $O$ experimentador leu a história em voz animada, com muita naturalidade, sem dar qualquer ênfase antes das pausas de cada palavra alvo. As crianças foram instruídas a repetir a última palavra cada vez que o narrador fizesse uma pausa e a pergunta do teste. Nenhuma indicação foi dada explicitamente quanto ao que o pesquisador prentendia com a atividade.

\subsubsection{Teste 3 - A casa perfeita}

Essa atividade seguiu os mesmos passos adotados no primeiro experimento, porém sempre que houve uma pausa o experimetador fez a seguinte pergunta "qual foi a última coisa que eu disse?"

\subsubsection{Teste 4 - (Contagem de palavras)}

O pesquisador explicou para as crianças que leria algumas frases para familializá-las com a técnica experiental e, ao final, faria a seguinte pergunta "Quantas palavras têm na frase que eu disse?" Posteriormente o experimetador leu as frases que faziam parte do teste. Algumas frases apresentam números e outras não. As primeiras têm a intenção de averiguar se a criança vai confundir o número de palavras da frase com o número que expressa quantidade de algo. As segundas são colocadas como distratores, embora também tenham o objetivo de verificar a noção de palavra por meio da contagem.

As crianças foram informadas que, para realizar essa atividade, precisariam estar atentas porque o experimentador leria 10 frases em voz alta, em ritmo normal, sendo que, ao final de cada frase, o experimentador faria a seguinte pergunta: Quantas palavras têm na frase que eu disse? Nenhuma indicação foi dada explicitamente quanto ao que o pesquisador prentendia com a atividade.

Finalizada a coleta de dados, passaremos à sua análise, apresentada a seguir. 


\section{ANÁLISE DOS DADOS}

A análise proposta foi feita qualitativamente, tomando os dados dos informantes de forma individual, de modo que pudéssemos nos deter na riqueza de suas individualidades para tentarmos entender suas concepções sobre o que entendem por "palavra" e se demonstram, por meio das atividades on-line ou off-line consciência sobre essa noção.

\subsection{Participante 1}

A menina, que vamos chamar de "l", com idade de 6 anos, participou ativamente dos testes, respondendo sempre que solicitada e, de acordo com suas respostas, parece não ter noção do que conta como uma palavra, embora não consiga explicar. Nos experimentos 2 e 3 , suas respostas basicamente ficaram restritas ao sentido da história, não nos revelando se há distinção entre "palavra" ou "coisa". No quarto experimento, a menina respondeu de forma aleatória as perguntas, demonstrando que não reconhece todas as palavras que estavam nas frases. De acordo com suas respostas, supomos que a menina encontra-se no Implícito (I), em que as representações ainda não estão disponíveis para qualquer análise. Podemos observar no exemplo em que o experimentador realiza, a seguinte pergunta: Tu consideras "até" uma palavra e por quê? Resposta: É. Pior que eu não sei.

\subsection{Participante 2}

Apresentaremos agora a análise da menina "M", com 6 anos. No primeiro experimento, em que foi solicitada para "responder para o Chico", apresentou grande sensibilidade para o conceito de palavra, pois explicou todos os porquês e, ao que parece, tem noção do que conta como uma palavra. Como podemos constatar na resposta apresentada para a seguinte pergunta: Tu consideras "as" uma palavra e por quê? Resposta: É. Porque se uma pessoa "dize" alguma coisa é uma palavra. 
No experimento 2, em que era para responder a última "palavra" que eu disse antes de pausar, a menina respondeu de modo geral toda a frase. Nos resultados para esse teste, parece apresentar uma noção confusa do conceito de palavra.

No experimento 3, que era para repetir a "última coisa", a menina respondeu exatamente igual ao teste anterior, confirmando nossa hipótese de que ainda tem uma noção confusa do conceito de palavra, como podemos observar nas repostas apresentadas para o experimento 3, fazendo comparações com as respostas apresentadas para o experimento 2 .

Vejamos o exemplo do experimento 3:

Pergunta: Qual foi a "última coisa" que eu disse?

Resposta: Tinha muitos animais.

Veja o exemplo do experimento 2:

Pergunta: Qual foi a "última palavra" que eu disse?

Resposta: Que morava numa casa.

No quarto experimento, em que foi solicitada para "contar palavras em frases", a menina contou, muitas vezes, as sílabas da palavra, o que nos levou a concluir que confundia o limite de sílabas com número de palavra, isto pode ser indício de que a criança pode estar, pelo nível de escolaridade, mais voltada a aspectos da fonologia do que da morfossintaxe. A criança, portanto, parece estar entre os níveis Explícito 1 (E1) para as tarefas em que tem de segmentar a palavra e no Explícito 2 (E2) para as tarefas de julgabilidade do que é palavra. Nesses níveis, as representações são explícitas, as de E2 disponíveis para acesso consciente, mas não para relato verbal, enquanto as de nível E1 ainda não.

\subsection{Participante 3}

Passemos ao menino "A", de 6 anos. No primeiro experimento, a criança demonstrou que está analisando as palavras, no sentido de identificá-las como tal, demonstrando ter alguma noção do conceito da mesma, mas ainda não consegue verbalizar as respostas. Vejamos um exemplo de resposta para a pergunta: Tu consideras "amigo" uma palavra e por quê?

Resposta: (Sim, com a cabeça). Amigo é uma palavra... porque é!

No segundo experimento, o menino apresentou comportamentos verbais diferentes e, de acordo com suas respostas, embora de maneira muito sutil, 
demonstrou ter mais sensibilidade para noção de palavras de classe aberta. Vejamos alguns exemplos, do experimento 2, em que era solicitado para responder a "última palavra" que o experimentador disse antes de pausar.

Resposta: Esperança.

Resposta: Sapatos

No terceiro experimento, em que era para responder a "última coisa" o menino "A" respondeu com as mesmas características do teste anterior. Vejamos alguns exemplos.

Resposta: Animais.

Resposta: Era.

No quarto experimento, o menino conta praticamente todas as sílabas das palavras, o que pode demonstrar que a criança pode estar, pelo nível de escolaridade, mais voltada a aspectos da fonologia do que da morfossintaxe. Nessa perspectiva, a criança parece ter alcançado o Explícito 2 (E2), perceptível pelas respostas adequadas, mas não há possibilidade de relato verbal, pois não explica suas respostas.

\subsection{Participante 4}

O menino "G", de seis anos, no primeiro experimento, parece ter uma noção confusa do conceito de palavra, pois admite e afirma que as "palavras" que eu disse são palavras, mas não sabe explicar, não sabendo os porquês. Vejamos alguns exemplos.

Tu consideras "beleza" uma palavra e por quê?

Resposta: É. Ai, eu não sei!

Tu consideras "até" uma palavra e por quê?

Resposta: Eu acho que não. Porque eu não sei muito disso aí.

No segundo experimento, demonstra ter mais sensibilidade para noção de palavras de classe aberta do que para palavras de classe fechada. Vejamos os exemplos. Ao ser solicitado para que respondesse a "última palavra" que o experimentador disse.

Resposta: Casa

Resposta: Sapeca.

Resposta: Triste. 
Resposta: Esperança.

No terceiro experimento, as respostas são muito semelhantes às do teste anterior, não havendo distinção entre "palavra" e "coisa". Vejamos alguns exemplos:

Pergunta: Qual foi a última coisa que eu disse?

Resposta: Animais.

Resposta: Felizes.

Respostas Monstro.

Resposta: congelado de medo.

No quarto experimento, o menino não demonstrou nenhuma sensibilidade na contagem de palavras em frases, usando a estratégia de contagem decrescente para responder o que foi solicitado. De acordo com suas respostas, o menino parece encontrar-se no Explícito 1 (E1).

\subsection{Participante 5}

A menina "I O", de 8 anos, no primeiro experimento demonstrou que parece ter adquirido o conceito de palavra porque, além de responder ao que foi solicitada, ainda apresentava exemplos. Como podemos observar na pergunta:

Pergunta: Tu consideras "até", "com" uma palavra e por quê?

Reposta: Sim, porque "até" a gente pode usar em palavras e em frases.

Resposta: Eu acho que sim. Ah, porque a gente pode usar em frases.

Já no segundo experimento, a menina parece ter uma noção confusa do conceito de palavra porque, sempre que solicitada, respondia a frase completa, e não a última "palavra", como podemos observar no exemplo a seguir, nas repostas para a "última palavra".

Resposta: o problema é que.

Resposta: Isa ficou muito triste.

Resposta: fazer alguns cartazes.

No terceiro experimento, quando solicitada a responder a "última coisa", a menina respondeu a última palavra que o experimentador disse. Vejamos alguns exemplos:

Resposta: Animais.

Resposta: em.

Resposta: casa. 
Resposta: Que.

O fato de demonstrar sua capacidade de segmentação, respondendo ao experimentador a "última coisa que ouviu", parece reforçar que ainda não há noção do que é uma palavra.

Já no quarto experimento, contagem de palavras em frases, a menina identificou todas as palavras, realizando a contagem tanto em palavras de classe aberta como as palavras de classe fechada. Esse é um resultado interessante, já que a criança parece apresentar comportamentos verbais relativos ao E3 no primeiro teste, em que explica o que é palavra, a seu modo, de E1 no segundo e no terceiro testes, em que tinha de segmentar "palavras" e "coisas" e de E2 no quarto teste, de contagem de palavras. Isso pode nos indicar que, uma vez que essas tarefas exigem habilidades diferentes, a criança pode revelar níveis de representação diferente, mesmo que a noção envolvida seja a mesma: a de palavra.

\subsection{Participante 6}

O menino "G A", de 8 anos, no primeiro experimento apresentou uma noção confusa em relação ao termo palavra, pois respondeu de forma ambígua, fazendo mais referência ao significado das palavras. Como podemos constatar nas respostas.

Tu consideras "amigo" uma palavra e por quê?

Resposta: É. São legais, amigo.

De acordo com os experimentos 2 e 3 , o menino não ter apreendido o conceito de palavra, pois respondeu de forma muito semelhante os dois testes, não fazendo distinção entre "palavra" ou "coisa", tendo suas respostas voltadas para o sentido da história.

O quarto experimento pareceu reforçar que o menino ainda não tem noção de palavra. De acordo com as respostas levantadas, o menino parece estar Implícito.

\subsection{Participante 7}

A menina " $\mathrm{J}$ ", de oito anos, no primeiro experimento demonstrou em suas respostas não ter apreendido o conceito de palavra. Entretanto, parece estar fazendo uma sutil reflexão sobre o que conta como uma palavra, tendo suas 
respostas mais baseadas no valor semântico das mesmas, exemplificando o uso dessas palavras e em alguns casos, ainda apresentando informações de ordem fonológica.

Pergunta: Tu consideras "amigo" uma palavra e por quê?

Resposta: É uma palavra porque o amigo nunca deixa de ser amigo, ele sempre fica brincando, ele conversa.

Pergunta: Tu consideras "com" uma palavra e por quê?

Resposta: É. Porque o "com" sempre no início, ou quando a gente vai começar uma palavra, sempre tem o com.

Pergunta: Tu consideras "ele" uma palavra e por quê?

Resposta: Considero porque "ele" pode ser um homem, um menino, um ursinho.

Nos experimentos 2 e 3, a menina não demonstrou distinção entre "palavra" ou "coisa", pois suas respostas foram semelhantes nos dois testes, respondendo a ambos os testes, praticamente toda a frase. Vejamos alguns exemplos.

Pergunta: Qual foi a "última palavra" que eu disse?

Resposta: Isa ficou muito triste.

Resposta: Isa quis dar uma caixa de sapatos

Resposta: Os cachorrinhos choravam de.

No quarto experimento, a menina "J" parece demonstrar que ainda não adquiriu o conceito de palavra porque, na contagem de palavras em frases, não reconhece as mesmas, realizando uma contagem aparentemente de sílabas. Vejamos alguns exemplos:

Pergunta: Quantas "palavras" têm na frase que eu disse?

1) Os três meninos estão jogando futebol.

Resposta: Doze

2) Eu gosto de estudar matemática.

Resposta: Doze

De acordo com as respostas levantadas, a menina parece estar no Explícito 1 (E1). 


\subsection{Participante 8}

O menino "N", de oito anos, no primeiro experimento parece fazer alguma reflexão sobre o que conta como uma palavra, pois procura dar exemplos de seu uso em frases e ainda afirma que é palavra, embora não saiba explicar. Vejamos um exemplo:

Pergunta: Tu consideras "até" uma palavra?

Resposta: É. Não. É, mas não sei explicar.

Nos experimentos 2 e 3,o menino não faz distinção entre "palavra" ou "coisa", respondendo de forma semelhante os dois testes. Suas respostas ficaram basicamente no sentido das histórias.

No quarto experimento, o menino parece fazer uma reflexão acerca da noção de palavra. De acordo com suas respostas, acredita-se que o menino tem noção desse conceito, e as representações estão explícitas para a mente, mas ainda não consegue verbalizar esse conhecimento, estando, portanto, no Explícito 2 (E2), pelo menos para as tarefas de identificação de palavra e de contagem.

\subsection{Participante 9}

O menino "H", de dez anos, no primeiro experimento parece ter uma noção confusa do conceito de palavra, mas já faz uma análise rudimentar, demonstrando o uso de algumas palavras em frases. Observe o exemplo:

Pergunta: Tu consideras "ele" uma palavra e por quê?

Resposta: Não porque ele... tu pode chamar ele, ele é estudioso, ele não é estudioso.

Pergunta: Tu consideras "as" uma palavra e por quê?

Resposta: Não porque "as" tu representa... tipo para começar uma frase. Tipo: As meninas são feias. As meninas são bonitas.

No experimento 2 e 3, responde igualmente aos dois testes, não fazendo distinção entre "palavra" ou "coisa", o que pode ser indícios de que ele sabe o que conta como uma palavra, embora ainda não consiga verbalizar esse conhecimento. O menino identifica, inclusive, palavras de classe fechada, como "que". Vejamos os exemplos:

Pergunta: Qual foi a "última palavra" que eu disse? 
Resposta: Casa.

Resposta: Que.

Pergunta: Qual foi a "última coisa" que eu disse?

Resposta: Animais.

Resposta: Que.

No quarto experimento, na contagem de palavras em frases, o menino confirma nossa hipótese de que sabe o que conta como uma palavra, pois realiza a contagem efetivamente das palavras na frase. Assim sendo, acredita-se que o menino entende o que conta como uma palavra e as representações estão explícitas para a mente, mas ainda não consegue verbalizar esse conhecimento, estando, portanto, no Explícito 2 (E2).

\subsection{Participante 10}

A menina " $N$ ", de dez anos, no primeiro experimento, demonstra ter conhecimento do que conta como uma palavra, porque, em suas respostas, geralmente apresentou exemplos do uso dessas palavras em frases. Sua noção de "palavra" está ligada ao uso. Vejamos alguns exemplos.

Pergunta: Tu consideras "até" uma palavra e por quê?

Resposta: Acho. Porque a gente diz: Até o supermercado.

Pergunta: Tu consideras "as" uma palavra e por quê?

Resposta: Sim. Porque a gente diz: as pessoas, as cadeiras.

No experimento 2, a menina respondeu de forma satisfatória o teste, acertando principalmente as palavras de conteúdo, que carregam significado. Já no terceiro experimento,que era para repetir a "última coisa", a menina acertou todas as questões,o que reforça nossa hipótese de que palavra é o que tem significado e não função gramatical. De acordo com suas respostas, parece que a menina está avançando para o nível Explícito 3 (E3), embora ainda não entenda que palavras de classe fechada também constituem palavras. 


\subsection{Participante 11}

A menina "T", de dez anos, no primeiro experimento, de acordo com suas respostas, tem uma noção confusa do que conta como uma palavra, pois procura apresentar significado para as mesmas. Como podemos observar no exemplo.

Pergunta: Tu consideras "amigo" uma palavra e por quê?

Resposta: Não. Porque pra mim amigo é um sentimento. Eu tenho um melhor amigo que tá sempre me apoiando.

Nos experimentos 2 e 3 , suas respostas foram muito semelhantes, pareceu não fazer distinção entre palavra e coisa, respondendo ambas as perguntas "qual foi a última palavra" e a "última coisa" praticamente toda a frase. Exemplos:

Resposta do experimento 2: Sapeca é um cachorro branco.

Resposta do experimento 3: Tinha muitas árvores e animais.

Já no quarto experimento, realizou a contagem de todas as palavras que continha nas frases. Parece que apenas no último teste a menina apresenta evidências de nível Explícito 2 (E2), enquanto parece estar no nível Implícito para os demais.

\subsection{Participante 12}

O menino "C", de onze anos, no primeiro experimento, parece ter uma noção do que conta como uma palavra, pois procura justificar suas respostas apresentando exemplo dessas palavras em frases. Aqui, também, a noção de palavra parece estar ligada ao uso. Vejamos alguns exemplos:

Pergunta: Tu consideras "as" uma palavra e por quê?

Resposta: É porque tu pode escrever "as árvores".

Pergunta: Tu consideras "quanto" uma palavra e por quê?

Resposta: É. Porque tipo, quando vou perguntar "quanto devo"?

Nos experimentos 2 e 3 não nos revela se faz distinção entre "palavra" ou "coisa", pois responde igualmente aos dois testes. Já no quarto experimento, o menino demonstra ter mais sensibilidade sobre o que conta como uma palavra, pois realizou a contagem de palavras em frases de forma satisfatória. Podemos considerar que o menino está no Explícito 2 (E2), para os últimos testes e no nível Explícito 3 (E3) para o primeiro. 


\title{
5 CONSIDERAÇÔES FINAIS
}

O trabalho aqui apresentado dedicou-se ao estudo do conhecimento de consciência de palavra apresentado por crianças falantes do Português Brasileiro e à sua relação com os níveis de representação mental postulados pelo modelo de Redescrição Representacional (Karmiloff-Smith, 1992).

Com aplicação dos testes e o levantamento das respostas obteve-se uma amostra do que as crianças entendem por palavra e de como uma informação implícita para a mente torna-se conhecimento explícito para a mente, ficando evidente que a consciência linguística não está relacionada à idade ou série, visto que crianças de 6 anos pareceram demonstrar indícios de nível E2, assim como crianças de 10 anos

Com relação ao modelo $\mathrm{RR}$, e com um olhar individual para os dados apresentados, o modelo aqui adotado, que vai além do simples implícito e explícito, consegue captar e explicar as sutilezas no desenvolvimento da linguagem, apresentando a possibilidade de percerber em que níveis da consciência linguística a criança está com relação à noção de palavra.

Para finalizar esperamos que este trabalho promova reflexão sobre consciência de palavra e que venha a contribuir para futuras dicussões sobre o tema.

\section{NOTAS}

${ }^{1}$ Graduada em Letras pela Universidade Federal do Pampa.

${ }^{2}$ Prof. Adjunto II da Universidade Federal do Pampa. Doutor em Linguística pela PUCRS.

\section{WHAT IS A WORD: LINGUISTIC AWARENESS IN CHILDREN FROM 6 TO 11YEARS OLD, BRAZILIAN PORTUGUESE SPEAKERS}

\begin{abstract}
This paper is placed in word awareness field and the relation with the levels of mental representation postulates in the model of representation description
\end{abstract}


(KARMILOFF-SMITH, 1992), in Brazilian Portuguese speaker's children. It was developed in four tests that aimed to descript the path in which the children representation becomes more malleable over time. Thus, it allows the emergency about aware assessment and about the implicit knowledge in relation to the notion of word. From the application of these texts and from the answers survey we hope to obtain a sample about the children understanding about the notion of word and about the implicit knowledge for the mind and how it becomes explicit in it. We believe in this work relevance because it enables an explication in the mental representations that found the knowledge about linguistic awareness presented in children.

Keywords: Language Acquisition. Linguistic Awareness. Representational Redescription Model.

\section{REFERÊNCIAS}

BERTHOUD-PAPANDROPOULOU, I. An experimental study of children's ideas about language. In: SINCLAIR, A.; JARVELLA, R. J.; LEVELT, W. J. (Eds.). The child's conceptions of language. Berlim: Springer-Verlag, 1978. p. 55-64.

DUBOIS, J. et al. Dicionário de linguística. São Paulo: Cultrix, 2006.

GOMBERT, Jean Émile. Metalinguistic development. London: HarvesterWheatsheaf, 1992.

KARMILOFF-SMITH, A. Beyond modularity: a developmental perspective on cognitive science. Cambridge (MA): MIT, 1992.

. From meta-processes to conscious access: evidence from children's metalinguistic and repair data. Cognition, n. 23, p. 95-147, 1986.

LORANDI, A. From sensitivity to awareness: the morphological knowledge of Brazilian children between 2 and 11 years old and the representational redescription model. 2011. Tese (Faculdade de Letras - Doutorado em Letras)-Pontifícia Universidade Católica do Rio Grande do Sul, Porto Alegre, 2011.

LORANDI, A.; KARMILOFF-SMITH, A. D. From sensitivity to awareness: the morphological knowledge and the representational redescription model. Letras de Hoje, v. 47, p. 6-16, 2012.

(2013). A consciência morfológica e o modelo de redescrição

representacional. In: SCHERER, Lilian C. et al. (Org.). Estudos em aquisição da 
linguagem: I Seminário Internacional de Aquisição da Linguagem. Porto Alegre: EDIPUCRS, no prelo.

MOTA, M. (org.). Desenvolvimento metalinguístico: questões contemporâneas. São Paulo: Casa do Psicólogo, 2009.

NAZZARI, G. T. Panorama de pesquisas sobre consciência fonológica de crianças com desenvolvimento normal realizadas no Brasil - 1991 até 2009. 2010. Dissertação (Mestrado em Letras)-Pontifícia Universidade Católica do Rio Grande do Sul, Porto Alegre, 2010.

PRATT, C.; GRIEVE, R. The development of metalinguistic awareness: an introduction. In: TUNMER, W. E.; PRATT, C.; HERRIMAN, M. L. (Eds). Metalinguistic awareness inchildren: theory, research and implications. Berlim: Springer-Verlag, 1984. p. 2-11.

ROSA, Maria Carlota. Introdução à morfologia. 5. ed. São Paulo: Contexto, 2009. 


\section{APÊNDICES}

\section{Teste 1- Palavras do teste "Responda para o ursinho Chico"}

1) Amigo.

2) Com.

3) Beleza.

4) Até.

5) As.

6) Quanto.

7) Anel.

8) Ele.

9) Beijar.

10) Que.

Exemplo de pergunta: Tu consideras "amigo" uma palavra ou não? Por quê?

\section{Teste 2 - Qual foi a última palavra que eu disse?}

\section{Sapeca e Pirulito}

Era uma vez uma menina chamada Isa, que morava com seus pais em uma casa linda. Isa tinha uma paixão toda especial por animais e ela tinha dois grandes amigos, a Sapeca e o Pirulito. Sapeca e Pirulito são dois cachorrinhos adoráveis. Sapeca é uma fêmea toda branquinha e muito travessa, já Pirulito é um macho preto e muito bagunceiro, que passa o dia espalhando os brinquedos pela casa. Isa gosta do seu quartinho todo organizado, o problema é que Pirulito é desobediente. Certo dia Isa queria estudar para uma prova e os dois cachorrinhos estavam fazendo a maior bagunça. Foi aí que Isa pensou: vou soltar os dois para brincarem no pátio. Quando a noite chegou, Pirulito voltou para casa, mas Sapeca desapareceu. Isa ficou muito triste porque não encontrava seu animalzinho de estimação. Teve que contar para seus pais o que tinha feito e juntos resolveram fazer alguns cartazes e colar pela rua em que moram. Receberam muitos telefonemas de pessoas querendo ajudar e dando informações, mas a Sapeca não apareceu. 
Quando todos já tinham perdido a esperança, Sapeca voltou para casa com dois filhotinhos. Agora a família estava completa novamente. Isa resolveu pegar uma caixa de sapatos para fazer uma caminha para os filhotes e levou todos para seu quarto. Na primeira noite os cachorrinhos choraram de fome e pela ausência da mãe. Na manhã seguinte a mãe da Isa resolveu comprar uma casinha para a nova família e colocar na sala. E assim, no final da tarde todos se reuniam para brincar.

\section{Teste 3 - Qual foi a última coisa que eu disse?}

\section{A casa perfeita}

Esta é a história de Pedrinho, um menino tímido e muito sonhador. Morava com seus pais na cidade, mas era nas férias, na casa de seus avós, que tudo acontecia. A casa de seus avós ficava no campo e tinha muitas árvores, animais. Foi então que, junto com seu melhor amigo, Joaquim, em uma tarde ensolarada de domingo, tiveram a brilhante ideia de construir uma casa na árvore. Primeiro juntaram todo o material necessário e foram construir a casa com a ajuda de seu avô. Foram dias de trabalho árduo, e por fim, a casa estava pronta, era só alegria!

Os meninos pensaram em tudo, nas janelas, na porta e na mobília, tudo estava perfeito.Quando chegou à tardinha, resolveram que iam dormir na nova casa, juntaram cobertores, travesseiros, biscoitos e também uma lanterna.

Os meninos passaram horas conversando e estavam muito felizes porque agora tinham um espaço só para eles. Quando chegou a hora de dormir, aquele silêncio da noite, as coisas começaram a ficar difíceis. Pela janela, Pedrinho via algo em movimento, e Joaquim ouvia barulhos assustadores. Pedrinho ligou a lanterna e foi conferir o que estava acontecendo e aí voltou o silêncio. Resolveram deitar-se novamente, mas aquela sombra voltou a se mexer na janela e parecia um monstro enorme e assustador. Foram momentos de muito medo, e Joaquim começou a chorar. Pedrinho tentava acalmar seu amigo, mas, na verdade, também estava congelado de medo.Assim, desceram rapidamente da árvore e correrram em disparada para casa. Entraram porta adentro, gritando que havia um monstro terrível lá fora.

O vovô, que já esperava por isso, acalmou os dois amigos, dizendo que tudo era a sombra dos galhos da árvore e que não precisavam ter medo. 
E assim os meninos decidiram que a casa era perfeita, mas que só brincariam durante o dia.

Palavras do Teste 4 - Contagem de palavras
1) Os três meninos estão jogando futebol.
2) Eu gosto de estudar matemática.
3) Julia comeu dois sorvetes.
4) Os meninos estão jogando.
5) Mamãe saiu para trabalhar.
6) Eu comprei uma bicicleta nova.
7) Eu gosto de viajar com meus pais.
8) Meu amigo gosta de andar a cavalo.
9) Eu gosto de ouvir música.
10) Meu irmão é muito estudioso. 